Témoigner Témoigner. Entre histoire et mémoire

Getuigen Revue pluridisciplinaire de la Fondation Auschwitz

\title{
Rwanda aflevering 5. Rwandese rivieren en moerassen: herinneringsplekken van de volkerenmoord?
}

Rwanda : Épisode 5 - Rivières et marais rwandais : lieux de mémoire du génocide?

\section{Rémi Korman}

Traducteur : Gorik de Henau

\section{(2) OpenEdition} Journals

Édition électronique

URL : https://journals.openedition.org/temoigner/3602

DOI : $10.4000 /$ temoigner.3602

ISSN : 2506-6390

Cet article est une traduction de :

Rwanda : Épisode 5 - Rivières et marais rwandais : lieux de mémoire du génocide ? - URL : https:// journals.openedition.org/temoigner/3597 [fr]

Éditeur :

Éditions du Centre d'études et de documentation Mémoire d'Auschwitz, Éditions Kimé

\section{Édition imprimée}

Date de publication : 1 octobre 2015

Pagination : 152-155

ISSN : 2031-4183

Référence électronique

Rémi Korman, «Rwanda aflevering 5. Rwandese rivieren en moerassen: herinneringsplekken van de volkerenmoord?», Témoigner. Entre histoire et mémoire [Online], 121 | 2015, Online op 01 octobre 2016, geraadpleegd op 03 février 2022. URL: http://journals.openedition.org/temoigner/3602 ; DOI: https://doi.org/10.4000/temoigner.3602 


\section{( \\ Herinnerings- labo

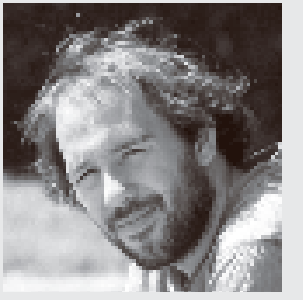 \\ $\rightarrow$ Door Rémi Korman, EHESS (École des Hautes Etudes en Sciences \\ Rwanda \\ Rymences. \\ RWANDESE RIVIEREN EN MOERASSEN: HERINNERINGSPLEKKEN VAN DE VOLKERENMOORD?} Sociales). Korman reist regelmatig naar Rwanda voor zijn onderzoek naar de genocide van de Tutsi's en het herinneringswerk daarrond. Samen met de vereniging lbuka in Lyon zet hij eveneens projecten op om die herinnering levendig te houden.

$\rightarrow$ Deze terugkerende rubriek moet inzicht verschaffen in de processen van herinneringsconstructie na 1994. Daarbij wordt rekening gehouden met de specifieke kenmerken van het herinneringsmodel in Rwanda, maar er is ook aandacht voor verbanden met studies over de Shoah, de Armeense genocide of de genocide in Cambodja.

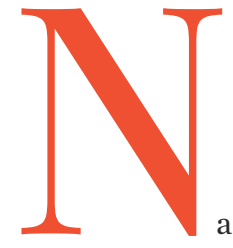

1994 houdt de Rwandese staat een herinneringspolitiek aan waarin de kwestie van de lichamen van de slachtoffers centraal staat. Het herdenkingsproces draait om het opgraven en waardig begraven. Maar hoe kunnen de overlevenden een herdenkingsplechtigheid organiseren als er geen lichaam is? Kun je op een symbolische manier herdenken? Iemands herinnering eren, wat betekent dat als er geen lichaam noch geijkte gedenkplek is?

In de context van die vragen ontstaan halfweg de jaren 2000 nieuwe manieren om de volkerenmoord te herdenken. Los van de staatsplechtigheden trachten verenigingen van overlevenden zich de slachtoffers van de genocide tegen de Tutsi's op andere wijze te herinneren, namelijk via themaherdenkingen. Er is bijvoorbeeld de Groupement des anciens de l'association des étudiants rescapés du génocide (vereniging van oud-studenten die de volkerenmoord overleefden), beter bekend onder de naam GAERG, die elk jaar een herdenking organiseert voor families waarvan alle leden zijn omgekomen (Imiryango yazimye muri jenosideyakorewe abatutsi). Maar er zijn ook - en daar zal het in dit artikel over gaan - de herdenkingen die worden georganiseerd door talrijke verenigingen van overlevenden, bijvoorbeeld Dukundane Family, ter nagedachtenis van de Tutsi's die in waterlopen, meren en moerassen werden geworpen.

\section{DE NYABARONGO-RIVIER}

\section{OF 'PAR LE RACCOURCI'}

Wie wil terugkomen op de rol van rivieren tijdens de volkerenmoord moet 


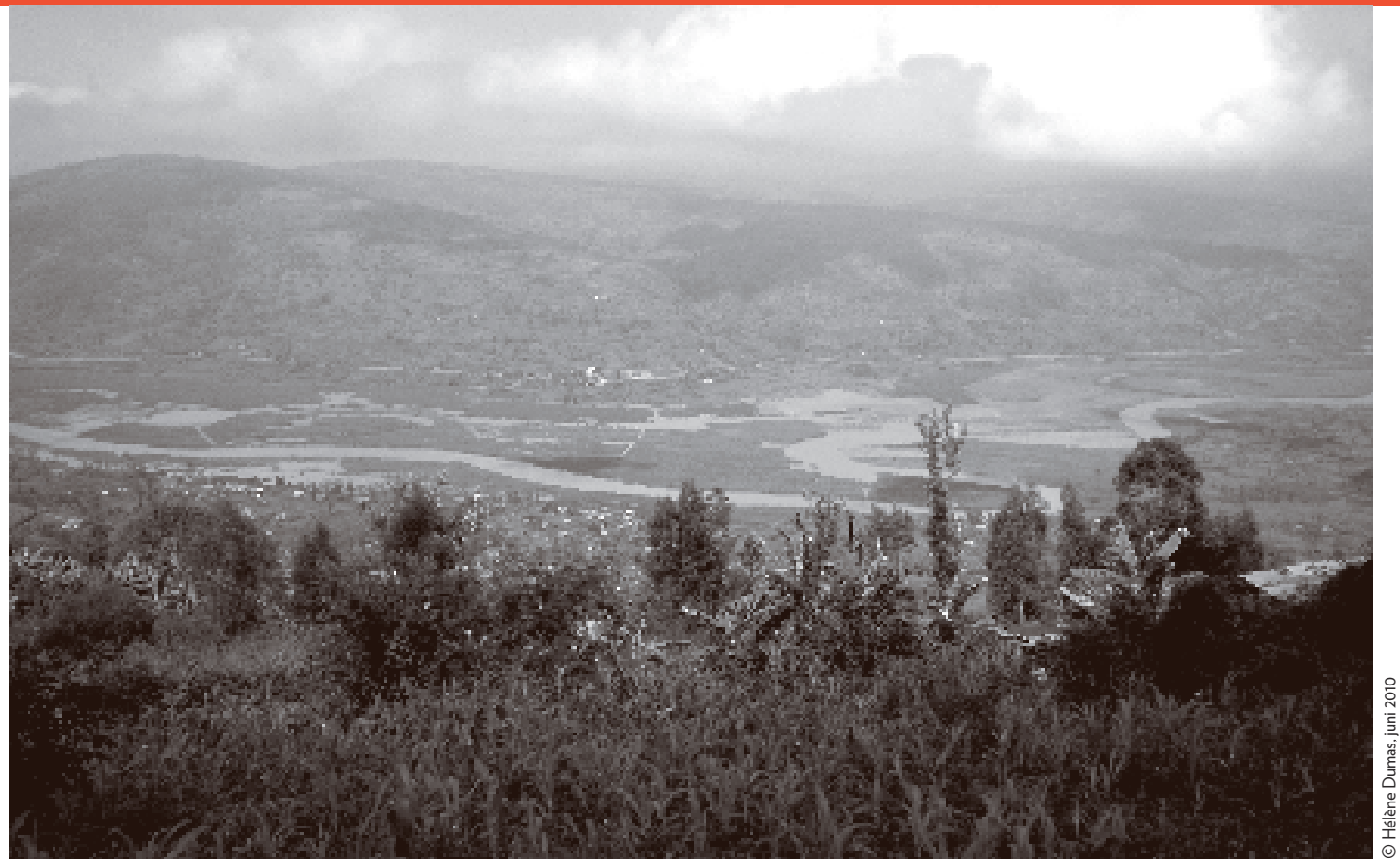

het hebben over de verschillende wijzen waarop de Rwandese bevolking tijdens het koloniale tijdperk wordt voorgesteld. Rwanda, vanaf eind negentiende eeuw beschreven als het land waar de Nijl ontspringt (waarvan de Nyabarongo een van de belangrijkste zijrivieren zou zijn), wordt door de kolonisatoren als een bijzonder koninkrijk beschouwd. De Tutsi-aristocratie maakt een sterke indruk op de eerste Europeanen, die vervolgens uiteenlopende theorieën uitwerken over bevolking en migraties in Rwanda. In die theorieën, grotendeels uit de lucht gegrepen en meestal krankzinnig, wordt de Tutsi-bevolkingsgroep voorgesteld als een 'ras' van buiten Rwanda. Die ideologie, door de onderzoeker Jean-Pierre Chrétien de hamitische ideologie genoemd, stelt dat het Tutsi-volk uit Ethiopië of Abessinië afkomstig zou zijn (Chrétien \& Kabanda 2013). De deels positieve ideologie, want de Tutsi's worden als 'valse negers' geclassificeerd, krijgt omstreeks de onafhankelijkheid een andere betekenis. Wat eerst als een positieve kwaliteit gold, wordt dan een stigma. De Tutsi's worden beschreven als indringers en later als parasieten.

Vanaf de eerste moordpartijen in 1959 worden de Tutsi's in de Rwandese waterlopen geworpen, vooral in de zijtakken van de Nyabarongo. Maar aan het begin van de burgeroorlog wordt de Nyabarongo in politieke toespraken pas echt een genocidale topos. Tijdens een meeting in Kabaya in 1992 houdt de Rwandese intellectueel Léon Mugesera een inmiddels beroemde toespraak waarin hij oproept om de Tutsi's 'par le raccourci' (via de binnenweg) naar Ethiopië terug te sturen. Hij zegt: 'Kun je dan niet luisteren of lezen? Ik zegje dat jouw thuis in Ethiopië is, dat we jullie via de Nyabarongo zullen sturen, zodat jullie snel ter plekke zijn.'

Tijdens de volkerenmoord worden
_ De Nyabarongorivier, gezien vanaf de Nyarusangeheuvel in Shyorongi. 
•. effectief ettelijke duizenden Tutsi's dood of levend in de waterlopen gegooid. De lijken bereiken en masse het Victoriameer in Oeganda, op meer dan duizend kilometer afstand. De Rwandese kunstenaar Daddy de Maximo, zelf een overlevende van de volkerenmoord, wijdde een documentaire aan het vreemde lot van die slachtoffers. De film, waarvan de titel Par le raccourci verwijst naar de tijdens de volkerenmoord gebruikte uitdrukking, wordt buiten Rwanda weinig vertoond, vanwege de obsessief herhaalde, zeer gewelddadige scènes. Daddy de Maximo heeft het uitgebreid over de geschiedenis van de Nyabarongo, de manier waarop die werd voorgesteld en de slachtingen die er plaatsvonden. Hij vertelt vooral het verhaal van de tienduizenden lichamen die uit het Victoriameer werden opgevist en vervolgens begraven door Oegandese vissers.

Sinds 1994 bestaan er in Oeganda - Affiche van de documentaire van Daddy de Maximo, By the shortcut, 2009.

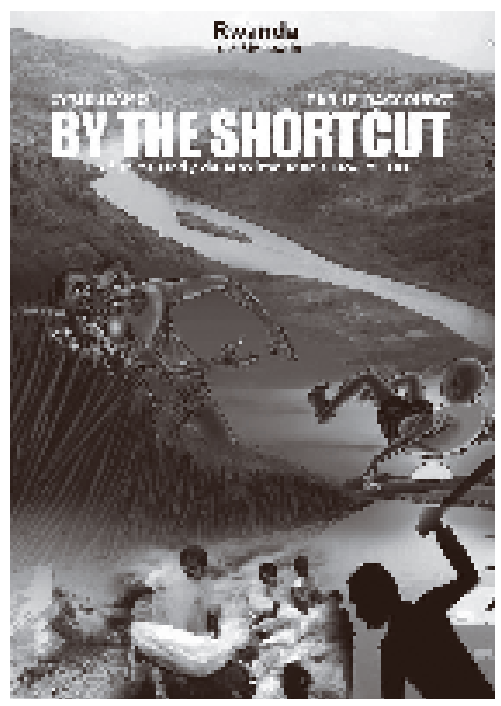
verschillende gedenktekens, maar de Rwandese staat wil drie grote monumenten oprichten in Ggolo, Kanseselo en Lambu. De Rwandese diaspora in Oeganda organiseert er al elk jaar herdenkingen. Vanuit Rwanda vinden er ook bedevaarten plaats. In dat verband is de Nyabarongo volgens de historicus Philibert Gakwenzire een 'herinneringsplek' geworden (Gakwenzire 2010).

\section{IBISHANGA OF DE \\ RWANDESE MOERASSEN}

Rivieren en andere waterlopen zijn niet de enige natuurplekken die in slachtplaatsen veranderden. De rol van moerassen in de volkerenmoord die in de gemeente
Nyamata (Bugesera) plaatsvond, komt trouwens in heel wat studies en literaire werken aan bod.

In Inyenzi ou les cafards (Inyenzi of de kakkerlakken) vertelt Scholastique Mukasonga hoe veel Tutsi's in 1959, tijdens de koloniale periode, naar deze moerasachtige streek werden gedeporteerd (Mukasonga 2006). Die gedwongen ontworteling, waarover nog geen geschiedkundig onderzoek werd verricht, verklaart de hoge Tutsiconcentratie in de gemeente Nyamata ten tijde van de volkerenmoord.

Jean Hatzfeld komt erop terug in zijn eerste boek Dans le nu de la vie: récits des marais rwandais, dat in 2000 verscheen. In alle verhalen beschrijven de geïnterviewde overlevenden de moerassen als een niet te overschrijden grens van de gemeente die door de rivieren Akanyaru, Mwogo en Nyabarongo wordt afgebakend. Voor de overlevenden zijn de moerassen een dubbelzinnige plek. In 1994 was het een plek waar je kon schuilen en overleven, en ook je dorst lessen met het water uit het suikerriet. Maar bovenal was het een plek van de dood, met stilstaand water, risico op malaria en moordenaars die elke dag op jacht gingen.

Berthe Mwanankabandi, een overlevende die Hatzfeld interviewde, vertelt:

We renden zonder na te denken in de richting van de Nyamwiza-moerassen. 's Avonds viel de regen onophoudelijk met bakken uit de lucht en we zochten een schuilplaats in de school van Cyugaro, in het eucalyptusbos niet ver van de moerassen. Dat zou een maand lang ons stapprogramma worden, van het moeras naar de school en terug. [...] Elke ochtend maakte ik voor de kinderen eten klaar met levensmiddelen die ik uit de 
grond had getrokken; daarna bracht ik hen naar een plek waar ze zich alvast konden verbergen onder het loof van de papyrus, samen met de grote mensen die geen energie meer hadden. Op zonnige dagen moesten we van plaats veranderen, vanwege onze voetafdrukken in het gedroogde slijk. De moordenaars zongen als ze eraan kwamen en dan was het onze beurt om ons te verspreiden in de moerassen. (Hatzfeld 2000, 176)

Hoeveel mensen zijn omgekomen in de moerassen rondom Nyamata en elders in Rwanda? Welk symbolisch graf krijgen de slachtoffers waarvan de lichamen niet uit de moerassen kunnen worden opgegraven? Ook op dat vlak zijn de laatste jaren nieuwe herdenkingswijzen ontstaan.

In april 2015 werden gedenkstenen opgericht 'aan de rand van het vlottende moeras van Ntarama, dat tijdens de volkerenmoord van 1994 meer dan 2000 Tutsi's opslokte. [...] Dit moeras, dat ook "het moeras van Rwimpiri (of het merkteken van de adders)" wordt genoemd, ligt doods en verlaten aan de voet van een eucalyptusbos, op de rotsachtige bodem van een steile heuvel. In april 1994 was het inderdaad het merkteken van de dood' (Rugiririza 2015).

Uit die tot dan toe onbekende herdenkingen blijkt hoezeer de verenigingen van overlevenden, maar ook de Rwandese staat, alle soorten plekken in overweging nemen die met de volkerenmoord verband houden. Zij gaan in tegen de gecentraliseerde herdenkingspolitiek die sinds 1994 wordt gevoerd en die er vooral in bestaat dat op de moordplekken grote nationale gedenktekens worden gebouwd, elk met een eigen symboliek. Het gedenkteken in Nyanza-Kicukiro staat symbool voor het ontbreken van enige tussenkomst van de VN in 1994, dat in Bisesero voor het verzet van de Tutsibevolking. In Nyamata, Ntarama en Nyarubuye wordt herinnerd aan de slachtpartijen in katholieke kerken. Met het gedenkteken in Murambi wordt dan weer de rol van Frankrijk gehekeld, want vanuit die plek werd Opération Turquoise geleid.

Tegenover die nationale en diplomatieke symboliek getuigen de nieuwe herdenkingswijzen van een decentralisering van de herdenkingspraktijk, waarmee de verenigingen van overlevenden te kennen geven dat ze willen terugkomen op de veelvuldige manieren waarop tijdens de volkerenmoord op plaatselijk niveau mensen werden terechtgesteld. .

(Vertaling: Gorik de Henau)

\section{BIBLIOGRAFIE}

- Jean-Pierre Chrétien \& Marcel Kabanda, $R$ wanda, racisme et génocide: lidéologie hamitique, Parijs: Belin, 2013.

- Daddy De Maximo, Par le raccourci, Kigali: Dadmax, 2009.

- Philibert Gakwenzire,

'Nyabarongo, une rivière du supplice', Dialogue 190, 2010, $8,23$.

- Jean Hatzfeld, Dans le nu de la vie. Récits des marais rwandais, Parijs: Le Seuil, 2000.

- Ephrem Rugiririza, 'Un marais mouvant érigé en mémorial du génocide', Agence Hirondelle, 21 april 2015.

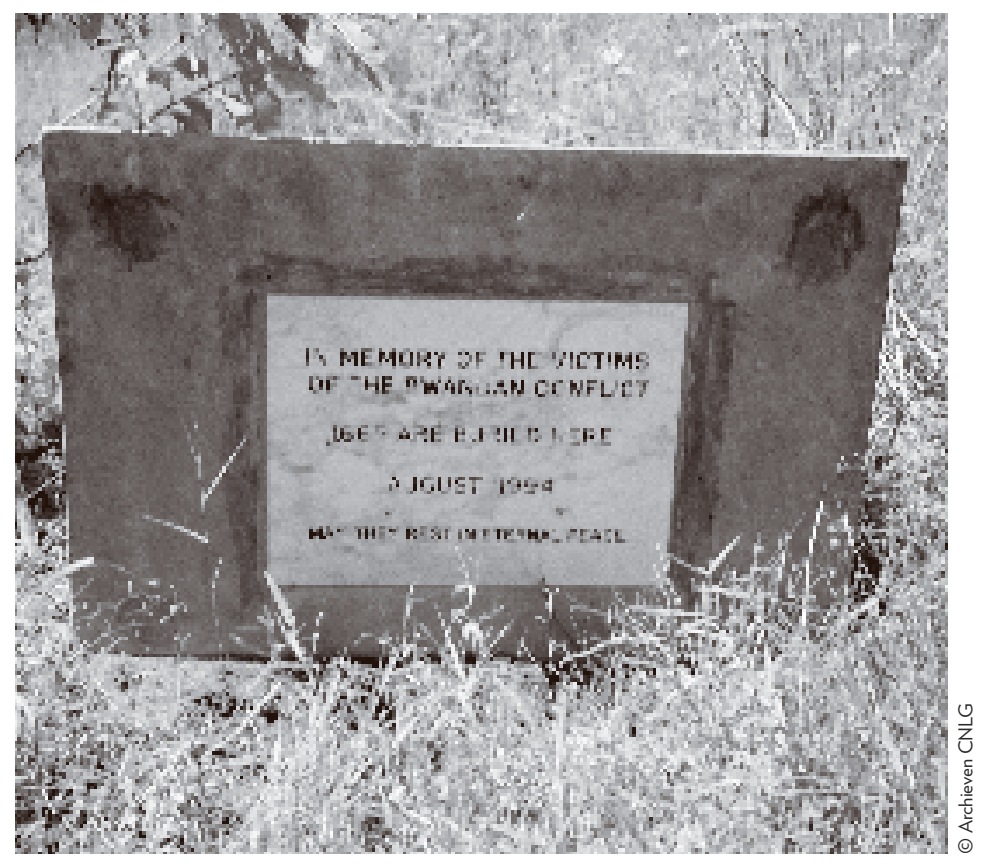

